\title{
Sensitivity of the WRF model to the lower boundary in an extreme precipitation event - Madeira island case study
}

\author{
J. C. Teixeira ${ }^{1}$, A. C. Carvalho ${ }^{2}$, M. J. Carvalho ${ }^{1}$, T. Luna ${ }^{3}$, and A. Rocha ${ }^{1}$ \\ ${ }^{1}$ Department of Physics, CESAM, University of Aveiro, Campus Universitario de Santiago 3810-193 Aveiro, Portugal \\ ${ }^{2}$ CENSE, Departament of Science Environmental Engineering, Faculdade de Ciências e Tecnologia, \\ Universidade Nova de Lisboa, 2829-516 Caparica, Portugal \\ ${ }^{3}$ IDAD The Institute for Environment and Development, Campus Universitario de Santiago 3810-193 Aveiro, Portugal \\ Correspondence to: J. C. Teixeira (jcmt@ua.pt)
}

Received: 2 August 2013 - Published in Nat. Hazards Earth Syst. Sci. Discuss.: 16 October 2013

Revised: 5 June 2014 - Accepted: 17 June 2014 - Published: 6 August 2014

\begin{abstract}
The advances in satellite technology in recent years have made feasible the acquisition of high-resolution information on the Earth's surface. Examples of such information include elevation and land use, which have become more detailed. Including this information in numerical atmospheric models can improve their results in simulating lower boundary forced events, by providing detailed information on their characteristics. Consequently, this work aims to study the sensitivity of the weather research and forecast (WRF) model to different topography as well as land-use simulations in an extreme precipitation event. The test case focused on a topographically driven precipitation event over the island of Madeira, which triggered flash floods and mudslides in the southern parts of the island. Difference fields between simulations were computed, showing that the change in the data sets produced statistically significant changes to the flow, the planetary boundary layer structure and precipitation patterns. Moreover, model results show an improvement in model skill in the windward region for precipitation and in the leeward region for wind, in spite of the nonsignificant enhancement in the overall results with higherresolution data sets of topography and land use.
\end{abstract}

\section{Introduction}

Topography plays an important role in atmospheric dynamics, as it can force flow dynamics and precipitation patterns and change atmospheric water vapour concentration. This relationship between topography and flow dynamics influences water vapour transport as well as the different precipitation forcing mechanisms, on a wide range of time and length scales. Therefore, and due to its pivotal influence on orographic precipitation understanding, this topic has been the subject of several studies for the past decade.

Due to the complexity of topographically forced mechanisms, studies concerning idealised situations such as the uniformly stratified moist flow over a Gaussian-shaped circular mountain have been performed by several authors, namely Jiang (2003), Colle (2004), and Kunz and Kottmeier (2006a). These works perform sensitivity studies in order to determine the relationship between the mountain's dimension and the precipitation intensity and distribution.

Under these assumptions, and using a mesoscale model, Jiang (2003) and Colle (2004) studied the interaction between flow stagnation and orographic precipitation. In their work, the authors showed that there is a significant relationship between the flow blocking and splitting effects and precipitation distribution and intensity. For low mountains the upslope ascent is dominant and the precipitation intensity is proportional to the mountain height and wind speed. On the other hand, for taller mountains the flow tends to pass around the barrier, reducing the lift effect. With regards to model parameters, Kunz and Kottmeier (2006a) showed that the results are less sensitive to model parameterisations than to ambient conditions.

In addition to idealised studies, real case studies have also been performed concerning the effect of mountain barriers on climate, interaction with synoptic-scale processes or even studies of single cases of extreme orographic precipitation 


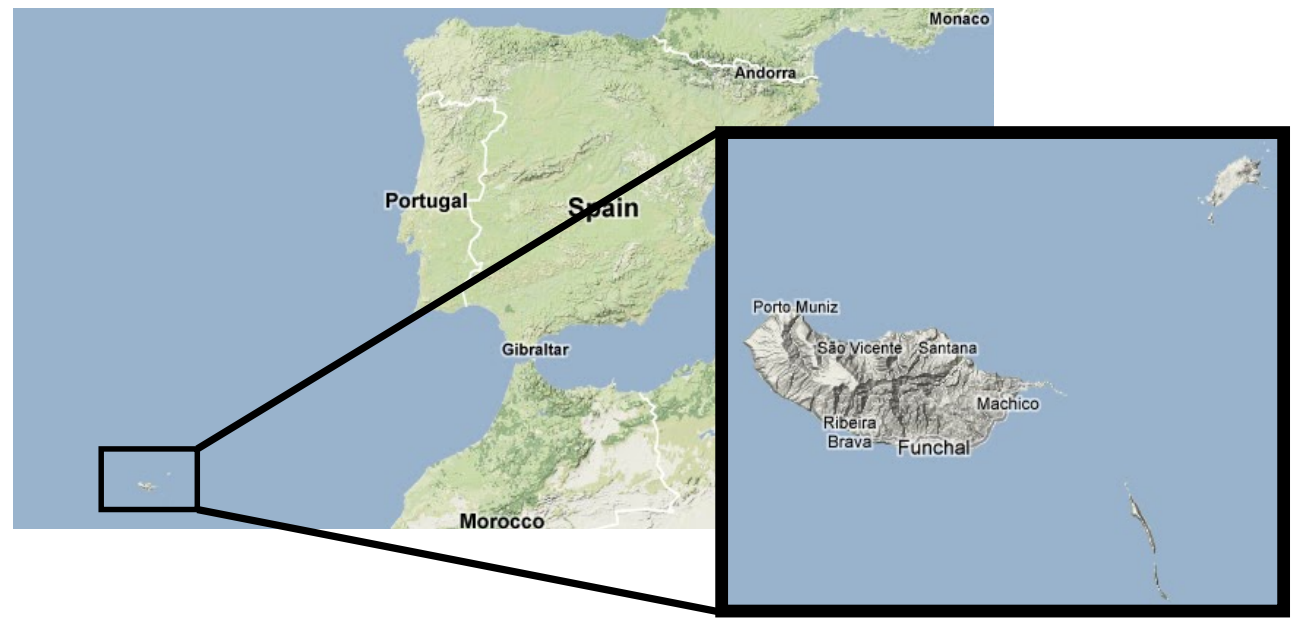

Figure 1. Study area map showing the Madeira archipelago location in the Atlantic Ocean; maps from www.googlemaps.com.

(Kunz and Kottmeier, 2006b; Maussion et al., 2011). Furthermore, atmospheric numerical models have been found to be useful in assessing precipitation in areas where observations are scarce and estimates are difficult (Maussion et al., 2011). As shown by several authors in multi-year studies, precipitation and flow patterns found on the island of Crete (Greece) have a strong correlation with the island topography (Kotroni et al., 2001; Koletsis et al., 2009, 2010; Vrochidou and Tsanis, 2012). This connection was found to be an important clue for spatial drought patterns. Concerning the synoptic-scale interaction, Ghafarian et al. (2012) studied the effects of the Anatolian and Caucasus mountains on the precipitation distribution over the Black Sea. For their research the authors performed the numerical simulation of a precipitating synoptic system passing through the study area. Using two different configurations, one with all the topographic features and another in which the mountains were removed, they concluded that, although there was a significant change in the fields of vertical motion, relative vorticity, humidity, low-level geopotential height, cloud water content and precipitation distribution, the mountains were not responsible for the cyclogenesis.

Shi et al. (2008) conducted a sensitivity study on precipitation patterns for the Tibetan Plateau. In one simulation the authors used a topography resolution consistent with the numerical model spatial resolution of $30 \mathrm{~km}$ and in the other a $120 \mathrm{~km}$ resolution topography that was then interpolated in order to be consistent with the model grid. Model results showed that the simulation with higher-resolution topography agreed with the observed precipitation. On the other hand, the simulation that used the coarser resolution underestimated the observed precipitation considerably. Besides the effects of topography on flow and precipitation patterns, Chen et al. (2001) showed how lower boundary conditions, for example soil moisture and land use, may affect precipitation and convection in a flash flood case study. Couto et al.
(2012) identified and studied four cases of intense precipitation over Madeira during the winter of 2009/2010 using both observed and simulated data. In their work the authors concluded that Madeira's orography is the dominant factor in both the formation and intensification of precipitation, altitude being the main factor contributing to the precipitation distribution. Using observed data, Fragoso et al. (2012) and Levizzani et al. (2013) also characterised the rainfall and the synoptic setting of the 20 February 2010 flash floods in Madeira, focusing on the dynamical conditions that promoted the extreme precipitation event.

Even though there are numerous works concerning topographic forcing in precipitation, little is known about the influence of different high-resolution lower boundary data sets in modelled results.

In the study presented here, a mesoscale numerical weather prediction model was used to assess the sensitivity of the model's lower boundary conditions to an extreme precipitation event. The chosen event occurred on the morning of 20 February 2010 over Madeira. This event was associated with a frontal system, embedded in a depression centred over the Azores archipelago, and moving to the northeast. The precipitation intensity triggered flash floods and mudslides, which had important social and economic consequences. Over 40 people died in the event and several houses and structures were damaged or destroyed.

Previous work had already studied the ability of numerical models to forecast this extreme precipitation event (Grumm, 2010; Luna et al., 2011), namely Grumm (2010), who analysed the ability of the National Center for Environmental Prediction of the United States of America ensemble global forecasting system (GFS) to forecast this event. They concluded that the pattern associated with the heavy precipitation event over Madeira was well predicted. Luna et al. (2011) also found that orography was the main factor explaining the precipitation event's amplitude and phase over 


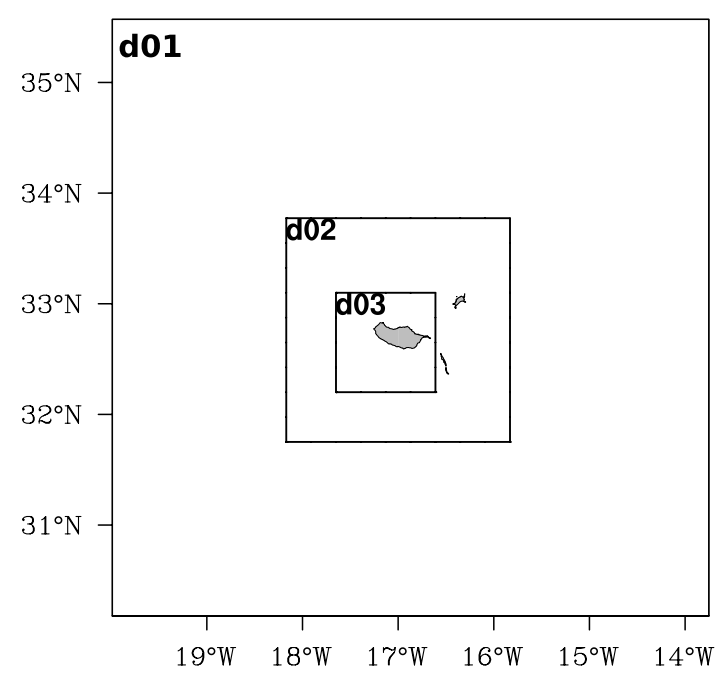

Figure 2. Three nested model domains used in WRF.

the island. Furthermore, this work showed that horizontal resolution is an important factor when simulating local precipitation.

We note, however, that this study considers only a single event with a very low probability of occurrence, but which is associated with high social and economic impacts. The authors believe that the results of the present study may contribute and, eventually, be generalised for different areas with similar characteristics and under similar conditions. With a probability of occurrence higher than once every 100 years, a statistical approach might not be possible to evaluate the climate (i.e. statistics) of these events.

\section{Methods and data}

In this work the Weather Research and Forecasting Advance Research (WRF-ARW) model version 3.3 (Skamarock et al., 2008) was used. Initial and lateral boundary conditions from GFS analyses (NCEP, 2003) were provided to the model at six-hour intervals. The GFS model has an approximated horizontal resolution of $0.5^{\circ} \times 0.5^{\circ}$ that extends vertically from 1000 to $0.27 \mathrm{hPa}$ in 64 unequally spaced model levels.

Madeira is located in the Atlantic Ocean southwest of mainland Portugal - Fig. 1. It has a mountain ridge extending along the central part of the island, reaching a maximum altitude of $1862 \mathrm{~m}$ - Pico Ruivo.

Three two-way nested domains were applied to the study area - Fig. 2: the parent domain (d01) with a horizontal resolution of $25 \mathrm{~km}$, and two nested domains (d02 and d03) with horizontal resolutions of 5 and $1 \mathrm{~km}$, respectively. Based on the forecast results obtained by Luna et al. (2011), the simulated period was $24 \mathrm{~h}$, starting at 00:00 UTC on 20 February 2010.

The set of parameterisations used in the present study was the same used by Luna et al. (2011) for the proposed
Table 1. Topography (bold) and land-use data set attributes

\begin{tabular}{lccc}
\hline & Resolution & Year & Soil Categories \\
\hline GTOPO30 & $\mathbf{3 0}^{\prime \prime}$ & $\mathbf{1 9 9 6}$ & N/A \\
SRTM & $\mathbf{3}^{\prime \prime}$ & $\mathbf{2 0 0 5}$ & N/A \\
ASTER & $\mathbf{1}^{\prime \prime}$ & $\mathbf{2 0 0 9}$ & N/A \\
& & & \\
USGS30 & $30^{\prime \prime}$ & 1993 & 25 \\
CORINE & $100 \mathrm{~m}$ & 2006 & 44 \\
\hline
\end{tabular}

event. The following schemes were therefore used: WRF single-moment six-class scheme microphysics (Hong and Lim, 2006), Goddard shortwave radiation (Chou and Suarez, 1999), the rapid radiative transfer model (RRTM) and a longwave radiation model (Mlawer et al., 1997), the Eta similarity surface layer scheme (Janjić, 2002), the MellorYamada-Janjic planetary boundary layer scheme with horizontal diffusion acting on horizontal gradients (Janjić, 1990), the Noah land surface model (Chen and Dudhia, 2001), and the Grell-Devenyi ensemble scheme as cumulus parameterisation (Grell and Dévényi, 2002) for domains d01 and d02. Due to the high resolution of the third domain (d03), the cumulus clouds are resolved explicitly (no cumulus parameterisation). The topographic correlation found in Jiménez and Dudhia (2012) was disabled in these simulations in order to reduce the alterations applied to model configuration to those directly related to the objective of the work in question. Furthermore, model sensitivity to microphysics schemes was not addressed in this work. However, an interesting overview of this subject can be found in the Fiori et al. (2014) work.

In order to conduct sensitivity tests of the topography and land use, several experiments were performed. In these experiments two topography data sets - the Shuttle Radar and Topography Mission (SRTM) (Farr et al., 2007) and the Advanced Spaceborne Thermal Emission and Reflection Radiometer global digital elevation model (ASTER) (Abrams et al., 2002) - and a land-use data set - the Coordination of Information on the Environment Land Cover (CORINE) (Bossard et al., 2000) - were used. A control (CTL) experiment was conducted with the WRF default topography data set - GTOPO30 - and the default land-use data set - USGS global $30^{\prime \prime}$ vegetation data (USGS30). Some of the more relevant data set attributes are described in Table 1.

Due to the different classification methods used in the CORINE and USGS global vegetation data, a recategorisation was performed on the CORINE data set in order for it to be recognisable to the WRF model. The recategorisation process used to convert CORINE into USGS categories is described in the Pineda et al. (2004) work. The performed simulations were grouped into two sets - control and lower boundary sensitivity (LBS) tests - as can be seen in Table 2 .

In order to analyse model results focusing on the evaluation of the WRF model's sensitivity to topography, the 
Table 2. Lower boundary conditions and microphysics schemes used in WRF simulations.

\begin{tabular}{lll}
\hline Simulation set & Run & Lower boundary condition \\
\hline Control & CTL & GTOPO30 + USGS30 \\
\hline LBS & SRTM & SRTM + USGS30 \\
& ASTER & ASTER + USGS30 \\
& CORINE & GTOPO30 + CORINE \\
\hline
\end{tabular}

difference fields between the experiments and the control simulation for precipitation, wind and other variables related to the planetary boundary layer (PBL) structure were computed. The Kolmogorov-Smirnov (K-S) statistical test which tests whether two samples are drawn from the same distribution at the $95 \%$ confidence level - was applied to each grid point time series in order to verify if model results are significantly different from each other.

In order to be able to study the effects of the upslope and downslope flows, the study domain was divided following the mountain ridge of the island. Finally, a more detailed study of simulated hourly precipitation and wind was pursued. Comparisons with observed hourly precipitation and wind data, as well as skills analysis for every experiment, were performed. To evaluate in detail the impact of using the new lower boundary condition data sets, Madeira was divided into the following regions, each one including a group of meteorological stations.

- Mountainous region $\longrightarrow$ Height greater than $800 \mathrm{~m}$, covering five stations - Areeiro, Bica da Cana, Calheta, Encumeada and Parque Ecológico do Funchal

- Shore region $\longrightarrow$ Height less than $800 \mathrm{~m}$, with seven stations - Funchal, S. Jorge, Lugar de Baixo, Ponta do Pargo, S. Martinho, Machico and Porto Moniz

- Windward region; nine stations - Funchal, Areeiro, Lugar de Baixo, Bica da Cana, Calheta, Encumeada, S. Martinho, Machico and Parque Ecológico do Funchal

- Leeward region; three stations - S. Jorge, Ponta do Pargo and Porto Moniz

In their study, Luna et al. (2011) showed that high model resolution enhances model skill in this particular event. Therefore the present work will focus on the domain with the highest resolution $-\mathrm{d} 03$.

Even though performance analyses and validation are usually done using state variables such as temperature and pressure, this study is focused on the Madeira extreme precipitation event and, therefore, only this variable together with wind will be analysed.

A total of 12 weather stations were considered, five of which are owned and operated by the Portuguese Meteorological Institute and which present only precipitation data -

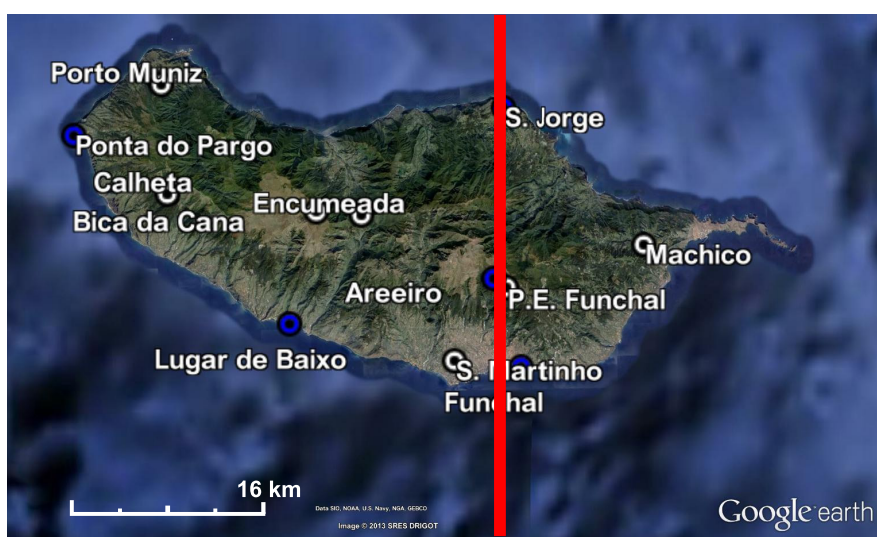

Figure 3. Location of the weather stations on Madeira (blue dotted - Portuguese Meteorological Institute; white dotted - Madeira Regional Civil Engineer Laboratory) and the cross section at $16.93^{\circ} \mathrm{W}$ used in this work (red line).

Table 3. Weather station information used to evaluate model skill operated by the Regional Civil Engineer Laboratory (bold) and the Portuguese Meteorological Institute.

\begin{tabular}{lccc}
\hline Location & Latitude $\left({ }^{\circ}\right)$ & Longitude $\left(^{\circ}\right)$ & Altitude $(\mathrm{m})$ \\
\hline Lugar de Baixo & 32.67 & -17.08 & 15 \\
Funchal & 32.64 & -16.89 & 58 \\
Machico & $\mathbf{3 2 . 7 3}$ & $\mathbf{- 1 6 . 7 8}$ & $\mathbf{1 7 0}$ \\
S. Jorge & 32.83 & -17.90 & 185 \\
S. Martinho & $\mathbf{3 2 . 6 5}$ & $\mathbf{- 1 6 . 9 4}$ & $\mathbf{2 5 0}$ \\
Ponta do Pargo & 32.81 & -17.26 & 312 \\
Porto Muniz & $\mathbf{3 2 . 8 4}$ & $\mathbf{- 1 7 . 1 9}$ & $\mathbf{6 7 5}$ \\
Encumeada & $\mathbf{3 2 . 7 5}$ & $\mathbf{- 1 7 . 0 2}$ & $\mathbf{1 0 1 7}$ \\
Calheta & $\mathbf{3 2 . 7 7}$ & $\mathbf{- 1 7 . 1 8}$ & $\mathbf{1 0 2 0}$ \\
P. E. Funchal & $\mathbf{3 2 . 7 0}$ & $\mathbf{- 1 6 . 9 0}$ & $\mathbf{1 3 0 0}$ \\
Bica da Cana & $\mathbf{3 2 . 7 6}$ & $\mathbf{- 1 7 . 0 6}$ & $\mathbf{1 6 0 0}$ \\
Areeiro & 32.71 & -16.91 & 1610 \\
\hline
\end{tabular}

Areeiro, Funchal, Lugar de Baixo, Ponta do Pargo, and S. Jorge. The other seven stations are owned and operated by the Madeira Regional Civil Engineer Laboratory and present precipitation and two-metre wind speed and direction data - Bica da Cana, Calheta, Encumeada, S. Martinho, Machico, Parque Ecológico do Funchal, and Porto Moniz. For both sets of weather stations, data is available on an hourly basis, for a period from 20 February 2010, 00:00 UTC to 21 February 2010, 00:00 UTC. Location and altitude information on these stations is shown in Table 3 and Fig. 3.

In order to produce vertical profiles of the atmospheric properties, a meridional cross section was defined at a longitude of $16.93^{\circ} \mathrm{W}$, considering all latitudes within the higher resolution domain d03, as can be seen in Fig. 3 .

To analyse the model performance for all simulations and compare them, the following statistical and error measures 
relative to observations were calculated (Keyser and Anthes, 1977; Pielke, 2002):

- Deviation of the modelled data in relation to observed values:

$\phi_{i}^{\prime}=\phi_{i}-\phi_{i, \mathrm{obs}}$

- Bias, which represents the mean deviation of the modelled data in relation to the observed values:

Bias $=\frac{1}{N} \sum_{i=1}^{N} \phi_{i}^{\prime}$

- The root mean square error:

$$
E=\sqrt{\frac{\sum_{i=1}^{N}\left(\phi_{i}-\phi_{i, \mathrm{obs}}\right)^{2}}{N}}
$$

- The root mean square error after the removal of a constant bias:

$E_{\mathrm{UB}}=\sqrt{\frac{\sum_{i=1}^{n}\left[\left(\phi_{i}-\bar{\phi}\right)-\left(\phi_{i, \mathrm{obs}}-\overline{\phi_{\mathrm{obs}}}\right)\right]^{2}}{N}}$

- Standard deviation for the modelled - Eq. (5) - and observed - Eq. (6) - data:

$$
S=\sqrt{\frac{\sum_{i=1}^{n}\left(\phi_{i}-\bar{\phi}\right)^{2}}{N}}
$$

$$
S_{\mathrm{obs}}=\sqrt{\frac{\sum_{i=1}^{n}\left(\phi_{i, \mathrm{obs}}-\overline{\phi_{\mathrm{obs}}}\right)^{2}}{N}},
$$

where $i$ is the temporal index and $N$ is the number of elements of $\phi$ considered.

Given this, a perfect forecast would observe the following criteria:

$-S / S_{\text {obs }}=1$,

- $E / S_{\mathrm{obs}}=0$,

- $E_{\mathrm{UB}} / S_{\mathrm{obs}}=0$,

- $\operatorname{Bias}^{2} / E^{2}=0$,

- and the Pearson Correlation $(R)$ would equal 1.

\section{Results and discussion}

\subsection{Synoptic pattern evolution}

Throughout the period under analysis, the synoptic pattern evolution over Madeira shows a rapid transition from highto low-pressure systems. Between 19 and 20 February 2010, the surface horizontal pressure gradient was weak and, at the $500 \mathrm{hPa}$ level, the island was flanked by a trough on the right and a ridge on its left side, and there were two depressions located near the Labrador Sea. By 20 February 2010, these two depressions had deepened and were moving westwards, forming a trough at mean sea level with a high on its right side. On 21 February 2010, western flux was imposed by the advection of these low-pressure systems to the west. Keeping in mind that precipitation analysis is dependent on horizontal model resolution, this discussion focuses only on the third nested domain.

When comparing the synoptic setting of this study with others that evaluate the orographic influence on precipitation (idealised studies by Colle, 2004 and Kunz and Kottmeier, 2006a, and a real data study by Kunz and Kottmeier, 2006b), some similarities arise. Madeira might be regarded as a singular barrier disturbing the synoptic flow, just as in most idealised experiments. During the simulated period the atmosphere is also stably stratified (not shown). Therefore, an enhancement in local precipitation over the windward side of the barrier and less precipitation on its leeward side due to the subsidence associated with the gravity waves is expected, as shown by Colle (2004) and Kunz and Kottmeier (2006a). In addition, the mountain crests of Madeira located perpendicularly to the main flow force the air mass to rise as it climbs the windward slope on the southern side of the island, capturing moisture on the orographically induced gravity waves on the northern side. This flow dynamics and its precipitation distribution pattern were also observed and studied by Luna et al. (2011) and Couto et al. (2012).

\subsection{Sensitivity to topography}

All simulations have the same grid resolution. However, due to the different topography and land use, data set interpolation was performed in order to have consistency with the CTL simulation, thus allowing for direct comparison between simulations.

Figure 4a shows the Madeira island topography that was used for the CTL simulation. Figures $4 \mathrm{c}$ and $4 \mathrm{~d}$ show the difference between CTL and SRTM (SRTM - CTL) and CTL and ASTER (ASTER - CTL), respectively. In addition, the topography of the cross sections used in this work for CTL, SRTM and ASTER is shown in Fig. 4b. As can be seen, the default topography tends to represent smoother topographic features. On the other hand, the high-resolution data sets present a better representation of those features, with higher peaks and deeper valleys as well as steeper terrain slopes. 


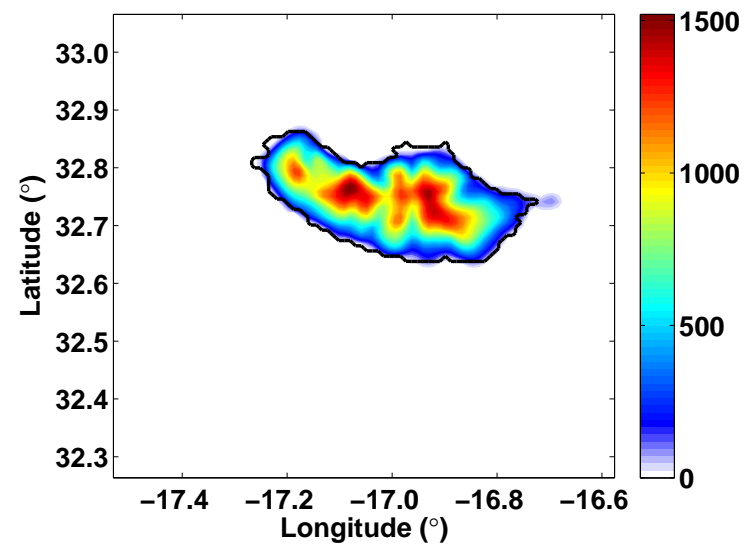

(a) Topography field from CTL simulation.

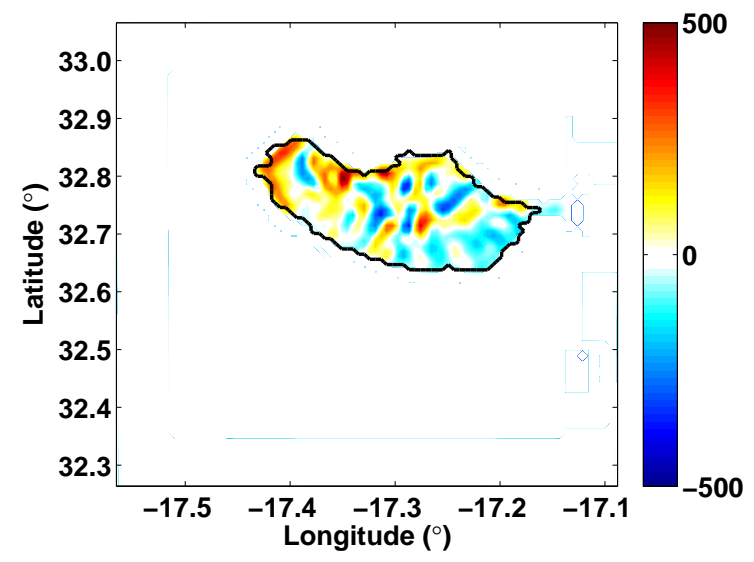

(c) SRTM - CTL

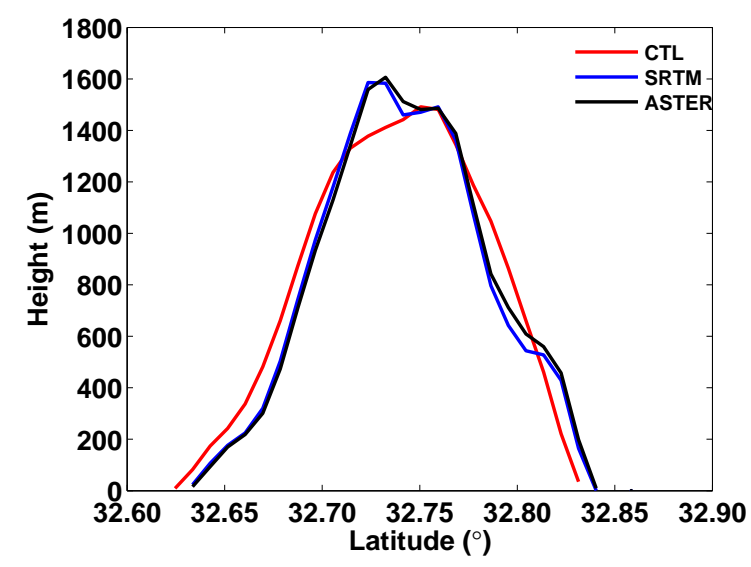

(b) Cross section

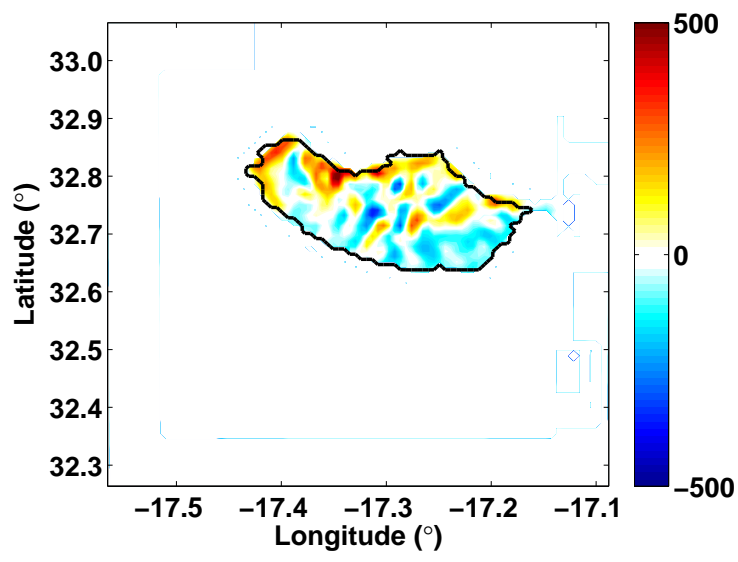

(d) ASTER - CTL

Figure 4. Topography field for the CTL simulation $(m)$ (a) and topography cross section $\left(16.93^{\circ} \mathrm{W}\right)$ for the three data sets, CTL (red), SRTM (blue) and ASTER (black) simulations (b), and difference fields $(m)$ between both high-resolution topography data sets and the control topography for domain d03 at a resolution of one kilometre ((c) and (d)).

These characteristics make it a better representation of the Madeira island topography.

With regards to the SRTM and ASTER data sets, both show a similar representation of the island topography, with only slight differences between them at the top of the island and on the middle northern slope.

\subsubsection{Wind-modelled data}

As seen before, topographically driven precipitation is highly dependent on flow intensity and direction (Jiang, 2003; Colle, 2004; Kunz and Kottmeier, 2006a). Furthermore, it is known that a change in topography may lead to a change in flow characteristics.

At the beginning of 20 February 2010, the simulated flow is perpendicular to Madeira's mountainous ridge - from the south - thus originating a deceleration zone upstream from Madeira, causing flow stagnation near the shore (not shown). Its weak intensity $\left(\sim 10 \mathrm{~m} \mathrm{~s}^{-1}\right)$ induces weak flow splitting, and therefore ascent flow is dominant. The strongest winds are reproduced by this model simulation right after the mountainous region - downslope - with an approximate intensity of $20 \mathrm{~m} \mathrm{~s}^{-1}$. Nonetheless, on the central northern leeward side of the island there is a weak flow zone from variable directions $\left(<5 \mathrm{~m} \mathrm{~s}^{-1}\right)$, created by the presence of the mountain ridge - the orographic shadow zone. This area suggests the presence of mountain waves downwind of the higher peaks of Madeira.

Later, at 12:00 UTC (not shown), the flow becomes more intense $\left(\sim 20 \mathrm{~m} \mathrm{~s}^{-1}\right)$. This flow intensification enhances the flow splitting, making flow intensity stronger near the eastern and western ends of Madeira. A proportional intensification of 10-metre wind intensity after the mountainous region is also noticeable. However, it can be seen that the upwind stagnation zone deepens into the island, becoming closer to the island peaks. In addition, on the central northern leeward side of the island, the weak flow zone becomes narrower due to the flow intensification at the western and eastern island 


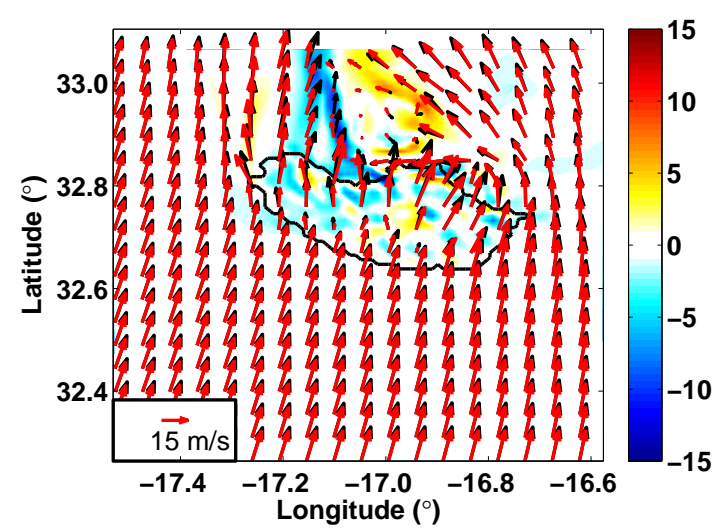

Figure 5. Difference field for wind intensity $\left(\mathrm{m} \mathrm{s}^{-1}\right)$ at the 10-metre height (shaded) between the SRTM and CTL simulations and wind direction for the SRTM (red arrows) and CTL simulations (black arrows) for 20 February 2010, at 12:00 UTC.

borders. After 18:00 UTC the flow weakens and changes direction to the west, becoming parallel to the Madeira island mountainous ridge. At this time, flow splitting becomes dominant due to the orientation of the wind in relation to the barrier. Therefore, despite not being shown here, a strong flow arises on the southern and northern Madeira shores.

Throughout the day, the difference field for wind direction and intensity maintains its characteristics, showing larger differences over Madeira and on its leeward side. The difference fields between SRTM and ASTER with CTL are very similar; thus, only SRTM will be presented.

The difference fields for wind intensity at the 10-metre level (shaded) between the SRTM and CTL simulations (SRTM - CTL) and directions (SRTM in red arrows and CTL in black arrows) for 20 February 2010 at 12:00 UTC are shown in Fig. 5. It is possible to observe that the greatest changes are located leeward, after the flow passes through the Madeira mountainous crests in an area where, for CTL simulation, the 10-metre wind intensity was weak, with a negative difference on the left side and a positive difference on the right side. The locations of these differences may suggest that there is a displacement of the orographic shadow zone between both SRTM and ASTER simulations when compared to the CTL data set. There is also an intensification zone - positive difference - for the high-resolution topography simulations near Ponta do Pargo. This area is located on the western end of the island, where the slope is steepest. Hence, the use of the higher-resolution data changes the model topography over this region of the simulated domain significantly, as can be seen in Fig. 4. This fact may affect the flow splitting, causing acceleration in this zone.

Figure 6 shows the difference in the mean wind speed at the 10-metre level between the SRTM and CTL simulations for 20 February 2010. Only differences for the grid points where the differences are statistically significant at the $95 \%$ confidence level are shown. It is possible to identify a number

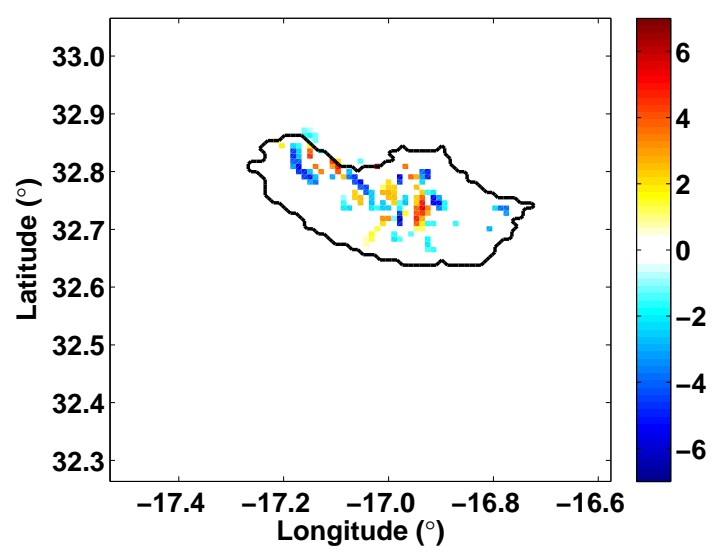

Figure 6. Difference field for mean wind intensity $\left(\mathrm{m} \mathrm{s}^{-1}\right)$ at the 10-metre level between SRTM and CTL simulations for 20 February 2010 , where the differences are statistically significant at the $95 \%$ confidence level.

of positive and negative differences that are statistically different over land. This suggests that topographic differences may change the flow path. These differences present a strong correlation coefficient with the topography difference field 0.606 for the SRTM simulation and 0.603 for ASTER (for all grid points), which rises to 0.834 for the SRTM simulation and 0.839 for ASTER when considering only the points where the differences are statistically significant.

\subsubsection{Changes to the PBL structure}

It is known that the PBL plays an important role in the whole atmosphere-Earth system, acting as an interface where the coupling between the atmosphere and the Earth's surface takes place. This interface contains most of the water vapour present in the atmosphere. The PBL has a great depth variation in both space and time, and it controls the transfer of momentum, heat and moisture between the atmosphere and the Earth's surface, leading to the control of the moisture transport within the troposphere (Deardorff, 1974; André et al., 1978). Given the interaction of the surface with the turbulent processes that occur within the PBL, understanding of the PBL interactions is crucial to the study of atmospheric dynamics as well as the improvement of our ability to understand model results for this event.

As seen in the previous section, there are significant changes in the 10-metre wind intensity, which may be related to a change in the PBL structure by changing the turbulent kinetic energy (TKE) or the vertical wind component.

Figure 7 shows the mean vertical wind component cross section for the CTL simulation (a) and the cross section for the mean vertical wind component difference between the SRTM and CTL simulations (b), where they are statistically significant at the $95 \%$ confidence level, for 20 February 2010. It is possible to see that there are large significant differences near Madeira's summit due to changes in SRTM 


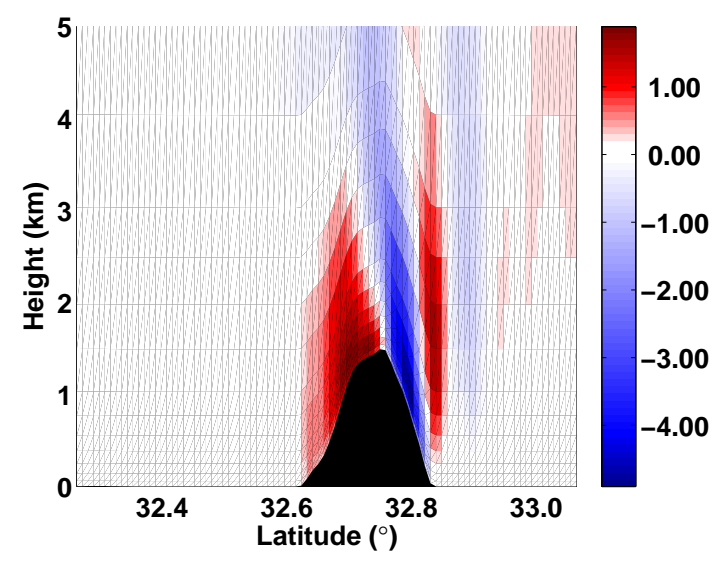

(a) CTL simulation.

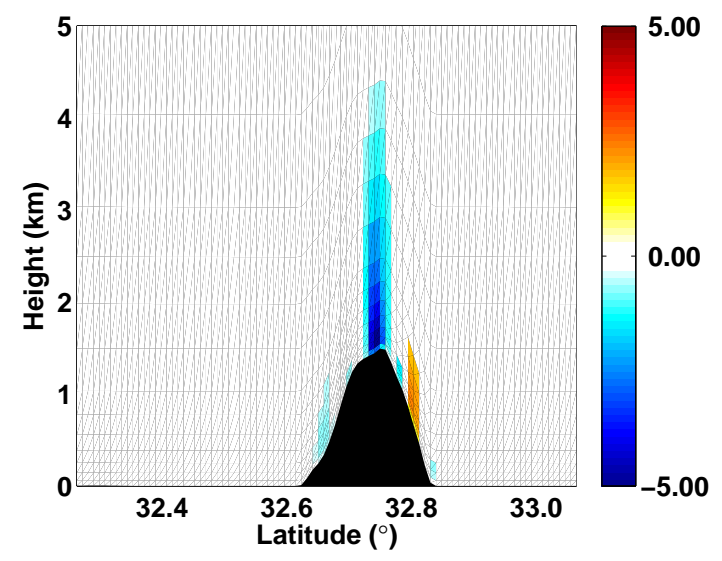

(b) Difference between SRTM and CTL

Figure 7. Mean vertical wind component cross section $\left(16.93^{\circ} \mathrm{W}\right)$ for the CTL simulation $\left(\mathrm{m} \mathrm{s}^{-1}\right)$ (a) and cross section for the mean vertical wind component difference between the SRTM and CTL simulations (b) for 20 February 2010; differences are only represented where they are statistically significant at the $95 \%$ confidence level.

and ASTER - Fig. 4b. There is a change in the location of the transition from upslope to downslope flow. It can also be seen that this change, forced by the topography, can reach levels in the lower troposphere up to heights above four kilometres. Nonetheless, an increase in vertical wind intensity (positive difference) can be found in the leeward region, showing that the change produced by the different data set might significantly perturb leeward flow processes such as gravity waves and turbulence. In fact, model results show an increase in the TKE in the first hundred metres near the summit of the island (not shown), which suggests that, besides the change in the position of the transition between the upslope and downslope winds, there is also an increase in the turbulent processes. For the ASTER simulation, identical patterns were found, only with smaller differences, and therefore it is not shown.

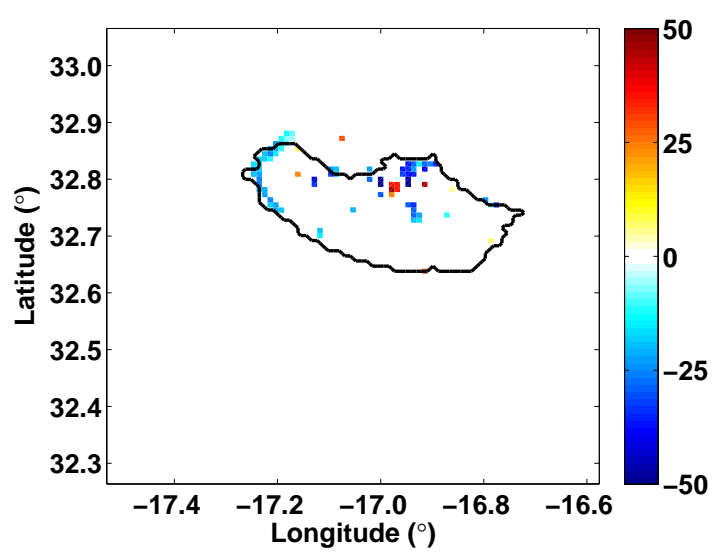

Figure 8. Relative difference field (\%) for the mean PBL height between the SRTM and CTL simulations for 20 February 2010, where they are statistically significant at the $95 \%$ confidence level.

Figure 8 shows the relative difference field $(\%)$ for the mean PBL height between the SRTM and CTL simulations for 20 February 2010, where they are statistically significant at the $95 \%$ confidence level. These differences are mostly negative, meaning that the higher-resolution topography results in a lower PBL over land. Moreover, comparing these results to the difference in topography (Fig. 4), it can be seen that there is a local PBL height reduction at grid points where the new data set presents a higher topography and vice versa, for example, at Ponta do Pargo at the western end of Madeira. Besides the statistically significant differences - considering the grid points that are not statistically different - model results show that there is an increase in the PBL TKE on the windward side and a decrease on the leeward side of Madeira. This pattern shows that the more detailed data set converts most of the flow into turbulent energy before it crosses the mountain barrier to the leeward side. Identical patterns were found for the changes in the PBL height for the ASTER simulation, albeit with slightly smaller difference values.

These results agree with those previously found for the vertical wind component and TKE, and show that the choice of a more detailed topography data set can change processes that occur in the PBL, and should therefore be considered. Given this, it is expected that the different topography data sets will produce differences in the PBL structure, and therefore differences in the available convective potential energy (CAPE) and convective inhibition (CIN) were computed.

Figure 9 shows the mean field of CAPE in the CTL simulation $\left(\mathrm{J} \mathrm{kg}^{-1}\right)$ (a), the relative difference field (\%) for the mean CAPE between the SRTM and CTL simulations (b), the relative difference field (\%) for the mean CAPE height between the ASTER and CTL simulations (c), the CIN mean field for the CTL simulation $\left(\mathrm{J} \mathrm{kg}^{-1}\right)(\mathrm{d})$, the relative difference field (\%) for the mean CIN between the SRTM and CTL simulations (e), and the relative difference field (\%) for the 


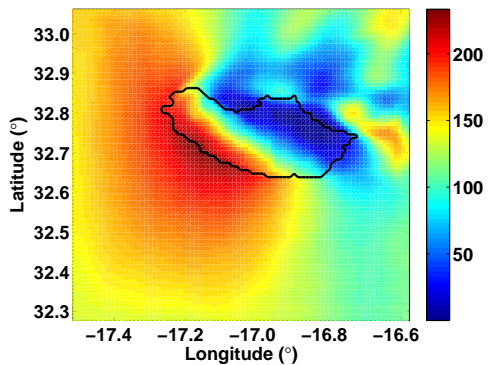

(a) CAPE for CTL simulation.

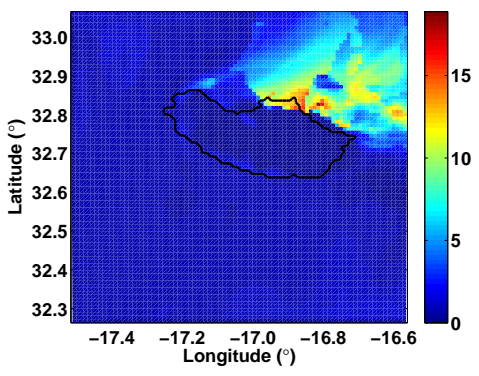

(d) CIN for CTL simulation.

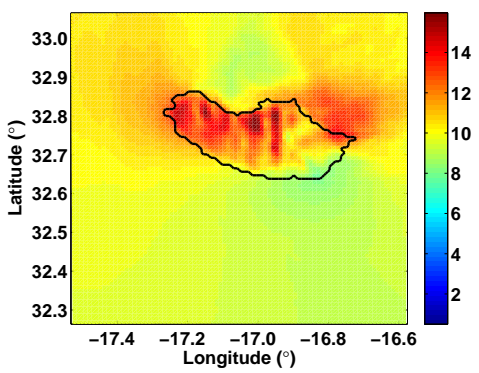

(g) BRN for CTL simulation.

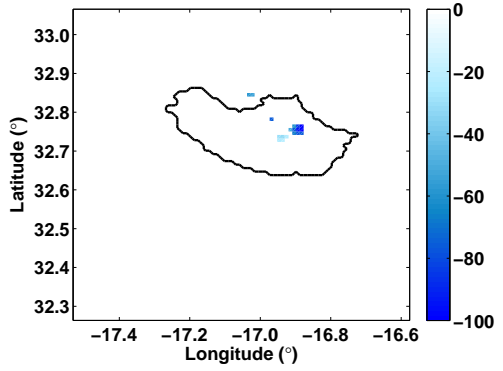

(b) CAPE difference (SRTM - CTL)

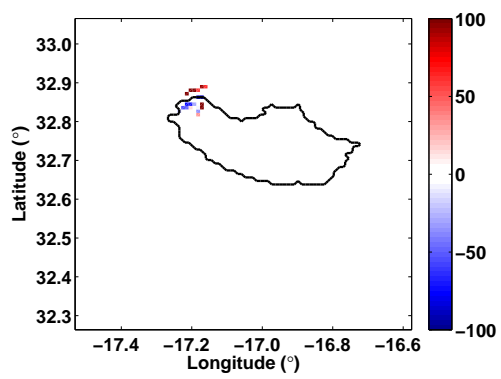

(e) CIN difference (SRTM - CTL)

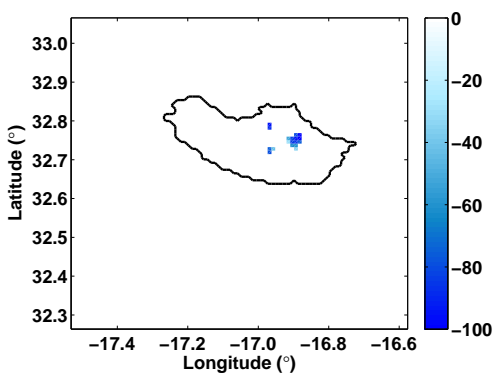

(h) BRN difference (SRTM - CTL)

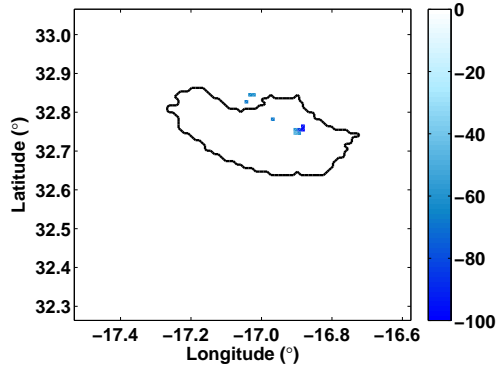

(c) CAPE difference (ASTER - CTL)

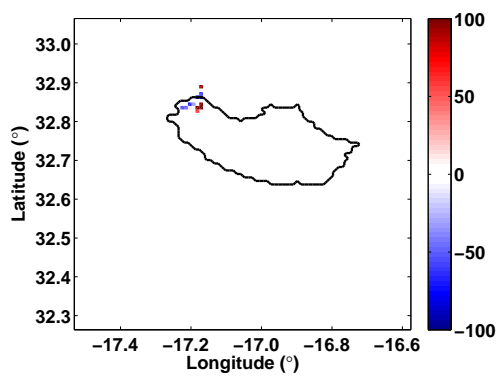

(f) CIN difference (ASTER - CTL)

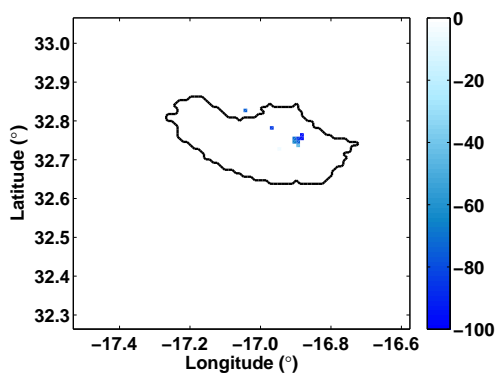

(i) BRN difference (ASTER - CTL)

Figure 9. CAPE mean field for the CTL simulation $\left(\mathrm{J} \mathrm{kg}^{-1}\right)$ (a), relative difference field (\%) for the mean CAPE between the SRTM and CTL simulations (b), relative difference field (\%) for the mean CAPE height between the ASTER and CTL simulations (c), CIN mean field for the CTL simulation $\left(\mathrm{J} \mathrm{kg}^{-1}\right)(\mathbf{d})$, relative difference field (\%) for the mean CIN between the SRTM and CTL simulations (e), relative difference field (\%) for the mean CIN between the ASTER and CTL simulations (f), BRN mean field for the CTL simulation (g), relative difference field (\%) for the mean BRN between the SRTM and CTL simulations (h), and relative difference field (\%) for the mean BRN between the ASTER and CTL simulations (i) for 20 February 2010; differences are only represented where they are statistically significant at the $95 \%$ confidence level.

mean CIN between the ASTER and CTL simulations (f), for 20 February 2010. Differences are only represented where they are statistically significant at the $95 \%$ confidence level. In this figure it is possible to see that in the CTL simulation there are high values of CAPE before the flow passes the mountainous barriers, and lower values on the leeward side of the island. However, the values for this measure are very low, indicating very high atmospheric stability. In addition, this atmospheric stability can also be seen in the CIN field - Fig. 9 (d) - in which most of the domain shows that the energy needed to prevent an air parcel from rising from the surface to the level of free convection is small - between 0 and $5 \mathrm{~J} \mathrm{~kg}^{-1}$. These values, although still very small, can rise to $15 \mathrm{~J} \mathrm{~kg}^{-1}$ on the leeward side. So far it has been seen that during this event the atmosphere is thermodynamically stable. However, dynamical turbulence caused by wind shear can contribute to the initialisation of convection. The bulk Richardson number (BRN) provides information on the relationship between thermal stability and turbulence caused by wind shear, as it is the ratio between the CAPE and the magnitude of the wind shear between 500 and $6000 \mathrm{~m}$. For the CTL simulation the BRN field presents a small value, although rising over land, where it becomes significant ( $>10)$, showing that vertical shear dominates over buoyancy and that the vertical motion will likely be weakened by the shear. 


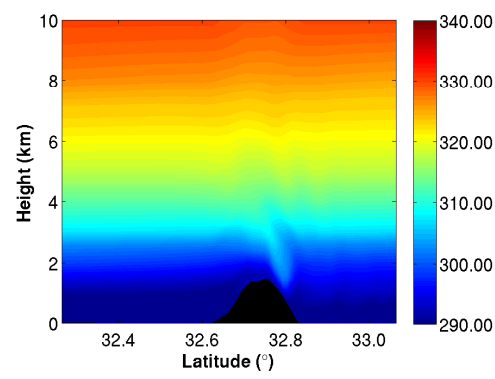

(a) CTL 06:00:00 UTC.

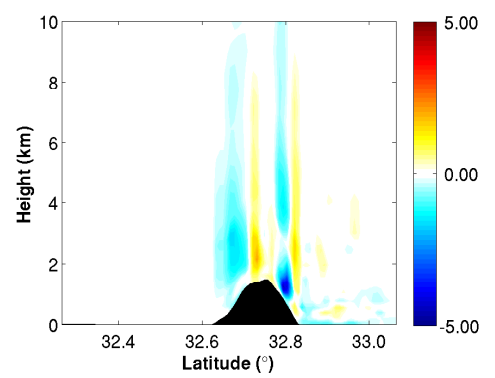

(d) Difference (SRTM - CTL) 06:00:00 UTC.

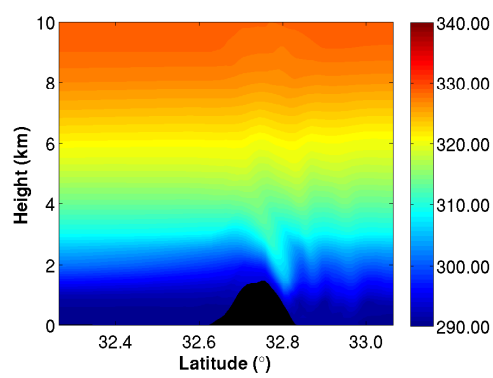

(b) CTL 09:00:00 UTC.

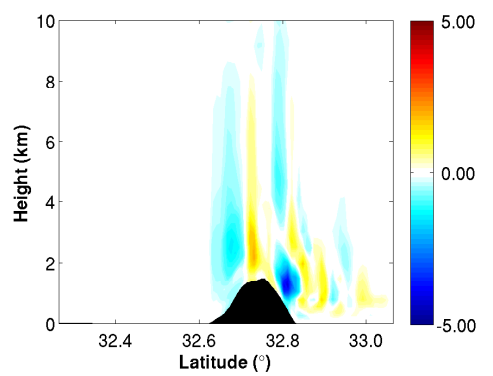

(e) Difference (SRTM - CTL) 09:00:00 UTC.

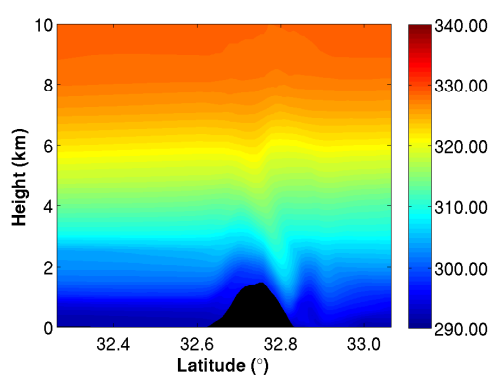

(c) CTL 12:00:00 UTC.

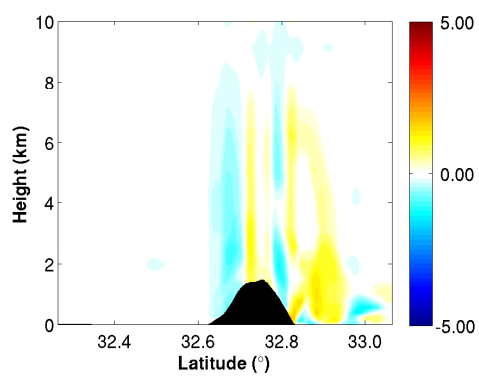

(f) Difference (SRTM - CTL) 12:00:00 UTC.

Figure 10. $\theta_{v}$ cross section $\left(16.93^{\circ} \mathrm{W}\right)$ for the CTL simulation $(K)$ at 06:00 UTC (a), 09:00 UTC (b) and 12:00 UTC (c), as well as the cross-sectional difference between the SRTM and CTL simulations at 06:00 UTC (d), 09:00 UTC (e) and 12:00 UTC (f).

The effects of the topography data set on these atmospheric indices can be found in Fig. 9. For both data sets, the grid points that present statistically significant differences for CAPE are located on Madeira's leeward side. Furthermore, it can be seen that, once again, SRTM and ASTER show similar patterns. Both simulations present a decrease in CAPE of approximately $20 \%$ in a region where the topography is more complex (location of the highest peaks and deepest valleys). This behaviour is not linked directly to the differences found in the topography field, but it occurs due to differences in the flow (the ones directly correlated with the change in topography). Before crossing the mountainous barrier created by Madeira, the wind rises and there is higher CAPE. This energy is then converted into convection that generates precipitation. After the flow passed the barrier (on the leeward side), much of this energy was used to develop convection and therefore was consumed by decreasing CAPE in this region - Fig. 9a. In addition, it should be noticed that for the SRTM simulation, there are grid points where differences are small - less than $20 \%$ relative to the absolute value of the CAPE - which shows that, albeit small, their distributions between the two fields (CTL and SRTM) are still significantly different. It can also be seen that BRN presents the same pattern, which, in turn, shows that these differences are dominated by unequal thermodynamic properties, which is to say that there are statistically significant differences for CAPE and not for wind shear. On the other hand, the CIN difference field shows statistically significant differences near Ponta do Pargo (western shore of Madeira). These fields show an increase near the coast and a decrease over land that is associated with the flow splitting differences described previously.

In order to understand the impact of the different topographies on the evolution of the event better, the virtual potential temperature $\left(\theta_{v}\right)$ for CTL simulations (top row) and its CTL and SRTM difference cross sections (bottom row) at 06:00, 09:00 and 12:00 UTC are shown in Fig. 10. When looking at the CTL cross sections, it can be seen that the atmosphere is highly stratified and therefore very stable. The time steps shown are representative of times before, during and after the event. The $\theta_{v}$ cross sections show an intrusion of air from higher levels of the troposphere on the leeward side of the island, which evolves during the event. Furthermore, following the event, there is a decrease in $\theta_{v}$, which is due to a lower water mixing ratio (not shown).

There are many differences between the STRM and CTL simulations in representing the position of the intrusion. These are mainly due to the changes in the upslope and downslope transition which were discussed previously. On the windward side, the vertical forcing to the flow occurs at different locations between simulations - in a more southern location for the SRTM simulation. Consequently, there is a spatial lag for the positions where the air rises and condensates. With the occurrence of precipitation at a more southern location for SRTM, there is a lower water mixing ratio for the same grid point - a negative difference value. Together 


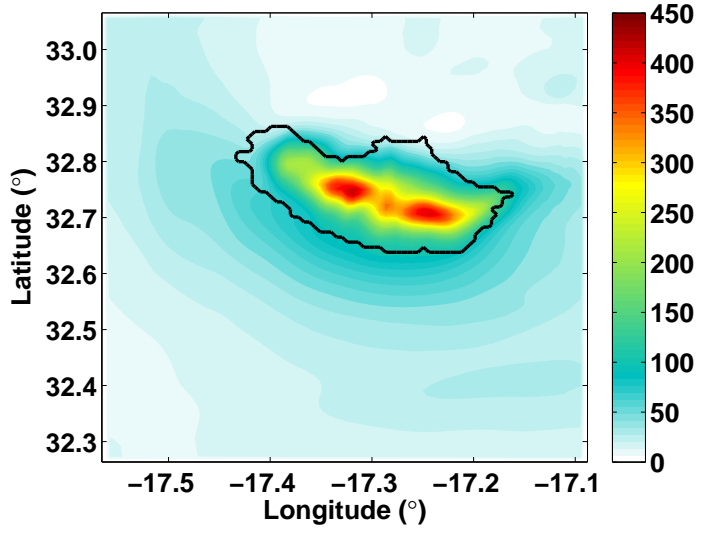

Figure 11. Accumulated precipitation $\left(\mathrm{mm} \mathrm{day}^{-1}\right)$ for 20 February 2010 for the CTL simulation.

with the different simulated position of the intrusion, this creates an increase in $\theta_{v}$ on the leeward side for SRTM. For the ASTER simulation, similar patterns were found and are therefore not shown.

\subsubsection{Precipitation modelled results}

As Luna et al. (2011), Couto et al. (2012) and Levizzani et al. (2013) have shown, this particular precipitation event was forced by topography flow lifting - orographic precipitation. Given the effect of a different topography data set on flow properties and the PBL structure, as seen in the previous subsection, differences in precipitation distribution and intensity are also expected.

Figure 11 represents the accumulated precipitation for the 20 February 2010 CTL simulation. High amounts of precipitation occur in the centre of Madeira near the highest peaks. It is also evident that in the southern part of the island - upstream from the main flow - there is a large amount of simulated accumulated precipitation, as would be expected. As it encounters the barrier - Madeira - the air is forced to rise. The rising moist air cools and creates favourable conditions for precipitation to occur. On the other side of the island - the northern part - there is a decrease in precipitation due to air subsidence and lower moisture content. The simulated accumulated precipitation amounts are therefore reduced in this area. This precipitation distribution and the patterns are consistent with those that Luna et al. (2011), Couto et al. (2012) and Levizzani et al. (2013) described for this particular extreme precipitation event.

When comparing the results of the SRTM and ASTER simulations with those of the CTL simulation, it is evident that differences occur over the island. Figure 12 shows the accumulated precipitation relative difference fields between the SRTM and CTL (SRTM - CTL) simulations for 20 February 2010 , where they are statistically significant at the $95 \%$ confidence level. The pattern of the difference field is similar for both simulations in amplitude and in distribution. Fur-

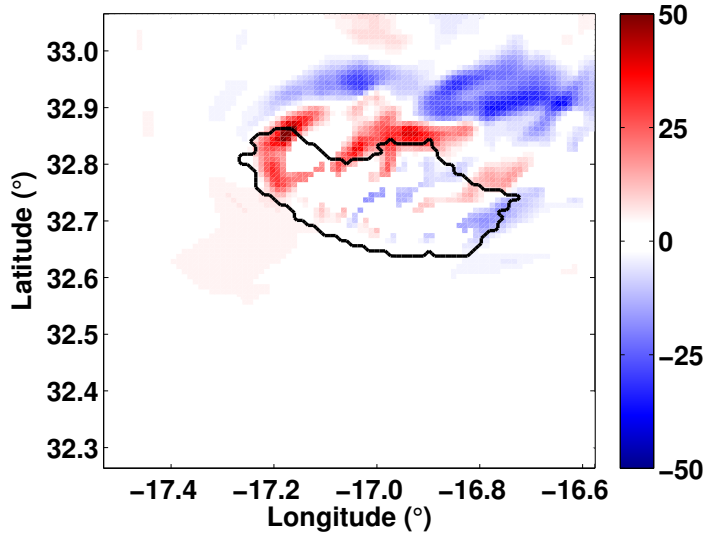

Figure 12. Relative difference field (\%) for accumulated precipitation between the SRTM and CTL simulations for 20 February 2010, represented where they are statistically significant at the $95 \%$ confidence level.

thermore, it is evident that in the western part of Madeira, most of the differences are positive, which shows that there is an increase in simulated precipitation. This region of the island is characterised by a steep slope followed by a plateau with a height of $1400 \mathrm{~m}$ that is oriented perpendicularly to the main flow. As seen before, the SRTM and ASTER simulations have a more detailed topography and, therefore, there is an increase in the terrain slope adjacent to the plateau. Consequently it is plausible that steeper slopes enhance the terrain forcing, leading to a stronger air rise that may then lead to an enhancement in topographically driven precipitation.

Centred on Madeira, it is possible to observe a negative value of the accumulated precipitation difference. This negative isolated difference is associated with a deep valley Ribeira Brava - located near the Lugar de Baixo weather station and extending to the top of Madeira. The obtained result in this area is consistent with the expected one: as the new high-resolution topography data sets tend to deepen the valleys, the area of the terrain forcing the air to rise is reduced, which may result in a decrease in precipitation.

The highest peaks of Madeira are located in its eastern region. However, near the eastern shore the slopes are not as steep as in the western region of the island. When using the high-resolution topography, this results in a decrease in precipitation near the Madeira shore - negative values of the accumulated precipitation difference - and an enhancement in precipitation in the eastern mountainous regions - positive values of the accumulated precipitation difference. Moreover, it can be seen that, in the leeward region, there is an increase in precipitation near the shore and a decrease off the coast of Madeira. On the one hand, this increase in precipitation develops as a result of the flow splitting that brings more moist air to this region. On the other hand, there is also a decrease in precipitation off the coast due to the depletion of 


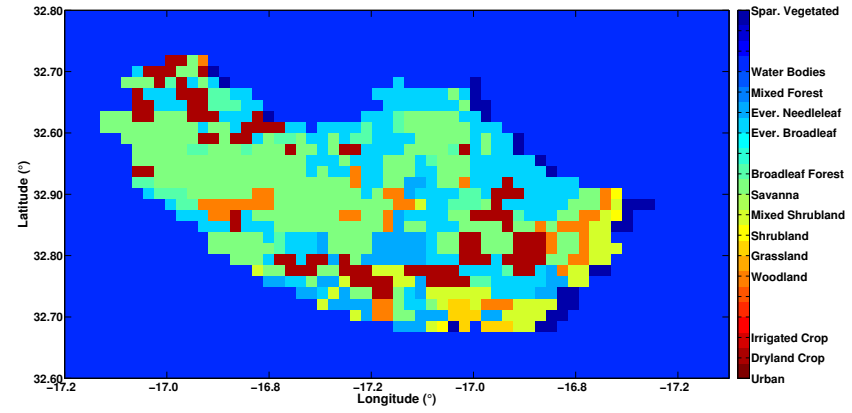

(a) CTL simulation.

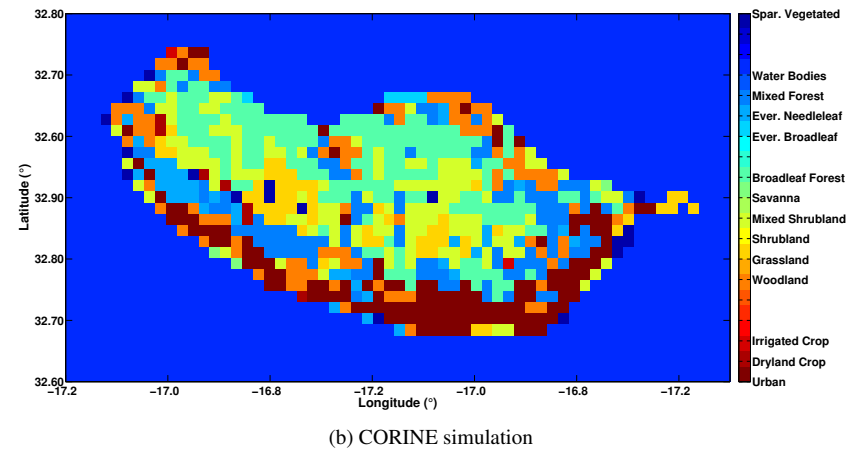

Figure 13. USGS land-use categories field based on the USGS (a) and the CORINE land-use data set (b).

moisture that the flow was subjected to by crossing Madeira with the different topography data set.

In addition, the correlation between the accumulated precipitation difference and the topography difference for both SRTM and ASTER is 0.36 and 0.46 respectively, at the $95 \%$ confidence level. These values, albeit small $(<0.5)$, show a relationship between the change in topography and the precipitation difference distribution, which rises to 0.40 for the SRTM simulation and 0.50 for ASTER when considering only the points where the differences are statistically significant.

\subsection{Sensitivity to land use}

As mentioned before, despite all simulations having the same resolution, the use of different data sets introduces differences into the modelled results. Contrary to topography, land use changes over a timescale typical of human activity and, therefore, land-use data sets may change significantly every time they are updated. In addition, it must be kept in mind that there is a 13-year time gap between the USGS and CORINE land use data sets used in this work.

Figure 13 shows the USGS land-use categories field for the CTL and CORINE simulations. It is possible to observe that there are differences in Madeira's coastline representation between the CTL and CORINE simulations. In fact, the CORINE data set provides the numerical model with a more realistic representation of the coastline as well as other geographic features. Furthermore, significant differ-

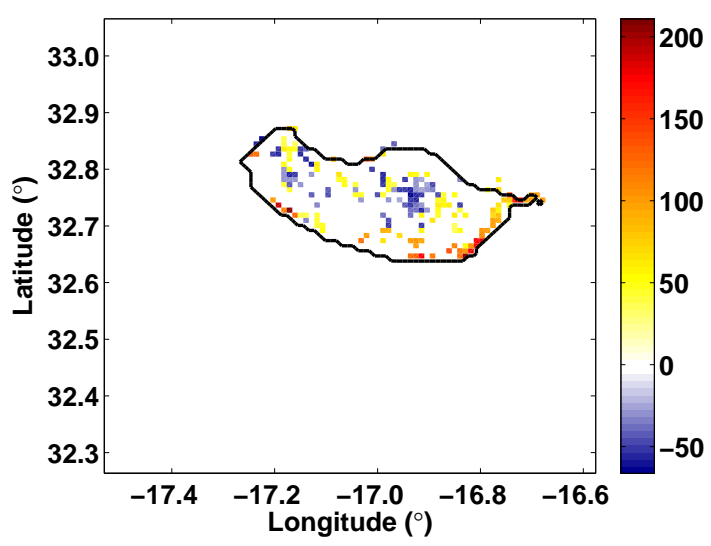

Figure 14. Relative difference field (\%) between the CORINE and CTL simulations for TKE (20 February 2010), represented where they are statistically significant at the $95 \%$ confidence level.

ences in land-use categories can be distinguished. For example, contrary to the CTL simulation, the urban and build-up land category is recognised by the model when the CORINE data set is used. Nonetheless, the area occupied by evergreen broadleaf and dryland cropland is reduced when the CORINE data set is used. Also, an increase in the area occupied by mixed forest and grassland can be observed. These changes between the CTL and CORINE simulations may lead to changes in flow proprieties and the turbulent processes within the PBL, due to changes in soil drag and the exchange of momentum (Chen et al., 2001).

It is known that changes in the roughness length, by changing the land use, can disturb the turbulent processes within the PBL. Figure 14 shows the relative difference field between the CORINE and CTL simulations for the 10-metre wind mean intensity - horizontal components - 20 February 2010 , only represented for the grid points where this difference is statistically significant at the $95 \%$ confidence level. It is possible to observe that the change introduced in the CORINE land-use data set produces large significant differences over Madeira. It can be seen that in Madeira's shore region there is an increase in the TKE and a decrease in the mountainous region. When analysing the land use considered by the simulations - Fig. 13 - in the areas where there is wind intensification and a reduction in the TKE, it is noticeable that it coincides with areas where the CTL considers the existence of deciduous broadleaf forest, whereas CORINE considers shrubland and grassland, which have a shorter roughness length. As a consequence, the latter has reduced surface wind drag over the considered area (Chen and Dudhia, 2001). On the other hand, in the shore region, where a decrease in TKE was observed, especially on the eastern end of the island, a significant change from shrubland and cropland to urban and mixed forest occurs, increasing the roughness length of the surface. 


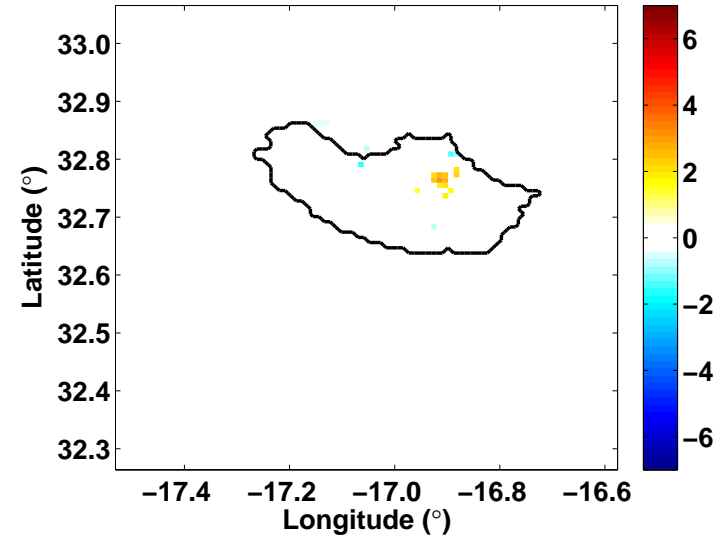

Figure 15. Difference fields between the CORINE and CTL simulations for the 10-metre wind mean intensity - horizontal components - 20 February 2010, represented where they are statistically significant at the $95 \%$ confidence level.

Despite this large, statistically significant change to the PBL TKE, no other significant changes were found to the PBL structure when the CORINE land use was used during this extreme precipitation event. Withal, this change to the TKE can also be reflected in the 10-metre wind intensity.

Figure 15 shows the difference field between the CORINE and CTL simulations for the 10-metre wind mean intensity for 20 February 2010. As can be seen, the differences produced by the use of the CORINE land-use data set for this particular precipitation event are small when compared to those produced by the use of a higher-resolution topography data set. For the mean horizontal wind component intensity, it is possible to observe that in the CORINE simulation there is a significant increase in the mountainous region of the island $\left(\sim 2 \mathrm{~m} \mathrm{~s}^{-1}\right)$. This corresponds to the same area where an increase in TKE was observed. This result shows that the increase in the roughness length in these grid points leads to an exchange of energy between the flow that crosses the island, being converted into turbulent energy. Despite not being statistically significant, a decrease in wind speed $\left(\sim 2 \mathrm{~m} \mathrm{~s}^{-1}\right)$ can be found around the Madeira island shore.

For accumulated precipitation (not shown), the difference values are smaller $\left(<20 \mathrm{~mm} \mathrm{~m}^{-2}\right.$ day $\left.^{-1}\right)$ than those previously seen for simulations in which topography was changed, and are only significant in a small area east of Madeira. Most differences are located upwind of Madeira, with positive difference values near Madeira's shore in an area of high density of urban and built-up land in the CORINE simulation, and negative differences in the mountainous region.

\subsection{Modelled results vs. observed data}

The previous analysis of the model results showed that, in this case study, the change to a high-resolution lower boundary condition data set leads to a change in model results for

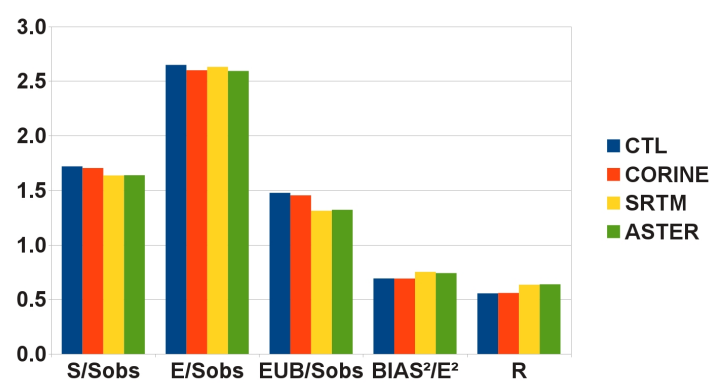

Figure 16. Skill chart for $v$ wind components.

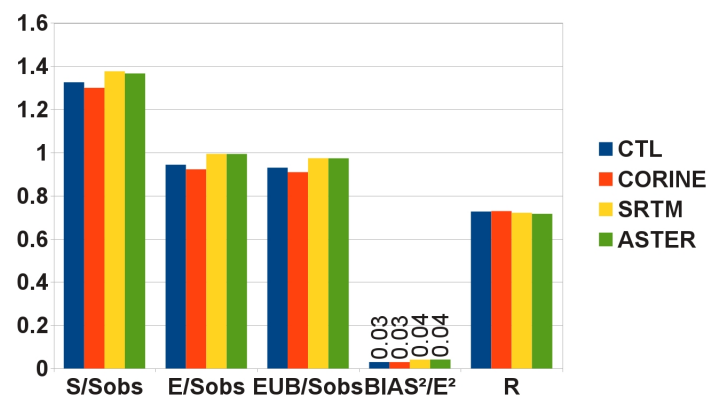

Figure 17. Skill chart for precipitation.

precipitation, wind direction and intensity. However, in order to know which one best represents the atmospheric conditions that were present throughout this event (20 February 2010), the comparison of modelled data with observed data is crucial. Therefore, the analyses of Taylor diagrams and skill charts between the model simulations and observed data were performed.

Figure 16 shows the skill chart for the $v$ wind component. This graph shows $S / S_{\mathrm{obs}}, E / S_{\mathrm{obs}}, E_{\mathrm{UB}} / S_{\mathrm{obs}}, \mathrm{BIAS}^{2} / E^{2}$ and $R$ between the simulation results and observed data for all stations where wind data were available. It is possible to see that for the $v$ wind component, there is an increase in the correlation for the SRTM and ASTER simulations when compared to the CTL simulation - from 0.55 to 0.64 - and that there is also a lower standard deviation for these simulations when compared to the observations $-S / S_{\text {obs }}<1$. On the other hand, for the $u$ wind component (not shown), the differences between the simulations are smaller. For this wind component, the use of a high-resolution topography data set slightly increases the correlation and standard deviation when compared to the CTL simulation. However, the standard deviation presents little change. For the CORINE simulation, changes in the statistical properties for both horizontal wind components are negligible, not presenting a significant change when compared to the CTL simulation.

In Fig. 17, the skill chart for precipitation is shown. Although it has a high ratio between the modelled and observed standard deviations $\left(S / S_{\text {obs }}>1\right)$, the model has skill in reproducing the observed precipitation, with most of the 


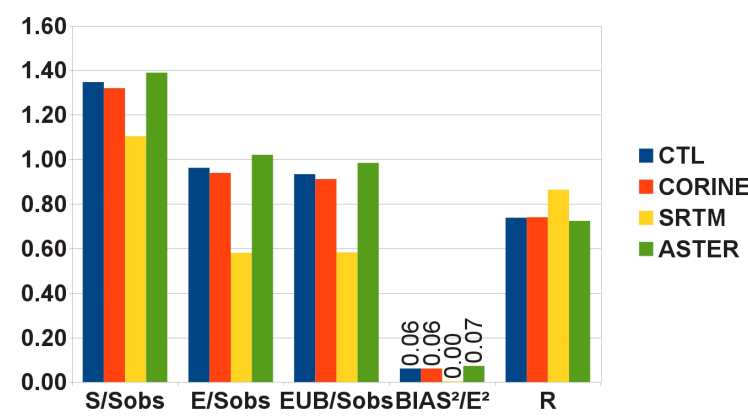

(a) Windward region

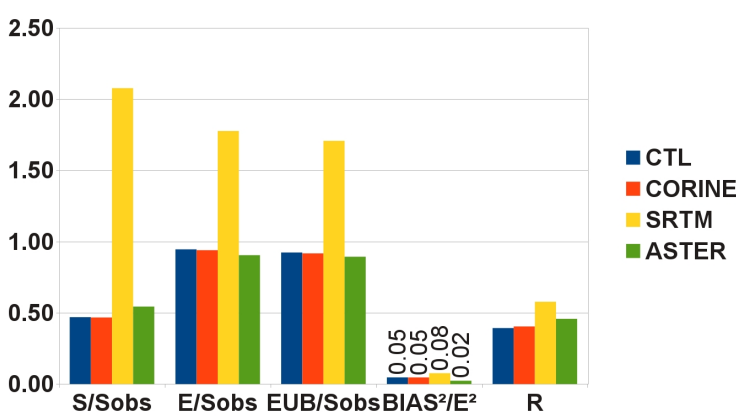

(b) Leeward region

Figure 18. Precipitation skill chart for the stations located in the windward (a) and leeward (b) regions.

criteria being met for all the performed simulations. Furthermore, it is possible to observe that differences between the simulations correspond to a small change in standard deviation, with the CTL and CORINE simulations having the values closest to the observed standard deviation $-S / S_{\text {obs }} \sim 13$ - and the SRTM and ASTER simulations showing worse results. Nonetheless, it is possible to observe that the SRTM and ASTER simulations present slightly higher standard deviations. However, there is little change in the correlation between the simulations and the observed data when comparing these simulations to the CTL and CORINE simulations. As for the wind data, with the use of a higher resolution and up-to-date land-use information - the CORINE simulation little enhancement in model skill is detected when compared to the CTL simulation.

A better evaluation of the changes in modelled data caused by the change in the lower boundary can be done by analysing the skill charts for the four Madeira sub-regions.

For the mountainous and shore regions, all simulations present similar skill results. There is poor model skill in reproducing the observed wind variability, especially for the $u$ wind component in all simulations $\left(S / S_{\text {obs }} \sim 3\right.$ for $u$ and $S / S_{\text {obs }} \sim 1.5$ for $\left.v\right)$. Moreover, a better representation of the wind intensity was obtained for the $u$ wind component for the SRTM and ASTER simulations (lower $E / S_{\text {obs }}$ than for the CTL simulation). However, these simulations present a larger value of $E / S_{\text {obs }}$ for the $v$ wind component than does the CTL simulation. On the other hand, for the shore region, the use of the high-resolution topography and land-use data sets enhances the model skill for $v$ variability and intensity. Contrarily, there are no major differences in skill measures between simulations for the $u$ component. For precipitation there is high skill in simulating precipitation in the shore region - every skill criteria is verified - although skill measures for different simulations are identical, having only negligible variations. For the mountainous region there is skill in simulating precipitation even though the simulated precipitation variability is larger than the observed one $\left(S / S_{\text {obs }} \sim 1.5\right)$.
Furthermore, SRTM and ASTER present the worst skill for this variable in this region.

When separating the domain into the windward and leeward regions, larger differences between simulations arise. In the windward region, there is poor skill in simulating both wind components. As seen for the mountainous and shore regions, here the $u$ wind component also presents larger variability than the observations $\left(S / S_{\mathrm{obs}} \sim 1.8\right)$. Nevertheless, the SRTM simulation presents a significant enhancement in skill when compared to the other simulations, namely, there is a decrease of $0.4 S / S_{\text {obs }}, E / S_{\text {obs }}$ and $E_{\mathrm{UB}} / S_{\text {obs. }}$. However, there is greater lag between this simulation and the CTL (larger value for $\mathrm{BIAS}^{2} / E^{2}$ ). For the $v$ wind component there are only small differences between simulations. In the leeward region, the CTL, CORINE and ASTER simulations present a very poor skill in simulating both horizontal wind components: $S / S_{\mathrm{obs}}>4.5, E / S_{\mathrm{obs}}>7$, and $R<0$. With the use of the SRTM topography data set, there is a significant improvement in model skill, with values $S / S_{\mathrm{obs}} \sim 2$, $E / S_{\text {obs }} \sim 2$, and $R>0.3$.

Figure 18 shows the skill chart for precipitation in both the windward region and the leeward region. In this figure, one can see that for the windward region there is skill in simulating the precipitation, despite the slightly higher modelled variability when compared to the observed one. Likewise for the windward data: only the SRTM simulation presents major changes when compared to the CTL simulation, with a significant enhancement in model skill. On the other hand, for the leeward region, there is also skill in simulating this atmospheric property despite the lower variability when compared to the observed $\left(S / S_{\text {obs }}<1\right)$. However, in this region the use of the SRTM topography results in poor model skill.

Still, it should be taken into consideration that differences found for skill in these regions are not only caused by the use of a different topography data set. When applying the criteria for these two regions (windward and leeward), stations located along the Madeira ridge are considered to be in the different regions for SRTM, ASTER and CTL. This change 
may occur due to differences in the location of the Madeira ridge in the SRTM when compared to all other data sets.

\section{Concluding remarks}

The WRF atmospheric model was used to assess the numerical model sensitivity to the lower boundary conditions in an extreme precipitation event. The event chosen was triggered by orography and occurred in Madeira - Portugal - on 20 February 2010 . The precipitation intensity produced flash floods and mudslides, which had important social and economic consequences.

Three different state-of-the-art high-resolution lower boundary condition data sets were used to simulate this event, thereby allowing the evaluation of the sensitivity to lower boundary conditions. The data sets used were SRTM and ASTER for topography, and CORINE for land use. The simulations started on 20 February 2010 and were extended for the following $24 \mathrm{~h}$, thus simulating the entire duration of the event.

Considering the default topography data used by the WRF model (GTOPO30) and the two other new topography data sets introduced in this work (SRTM and ASTER), changes can be observed in topography, albeit that all simulations have the same grid resolution. With the use of the highresolution topography data sets there is a deepening of the valleys and higher peaks, changes that can be greater than $100 \mathrm{~m}$, better representing the topographical features of Madeira.

Given these differences, a comparison between the simulations - CTL, SRTM and ASTER - was performed. It was possible to see that the use of any of the high-resolution topography data sets may lead to changes to the flow and PBL structure, specially over Madeira and in the leeward region. When analysing the results for horizontal components of the 10-metre wind intensity, it was seen that the high-resolution data sets presented a significant increase in the flow intensity in the valleys and a decrease in the peaks. This change was reverberated in the wind vertical component and PBL structure. For the vertical wind component it was seen that both simulations - SRTM and ASTER - showed a change in the location of the transition from upslope to downslope flow over Madeira's highest peak, propagating with smaller differences to the leeward region. In addition, and closely related to this modification, statistically significant changes to the PBL height were observed in the leeward region and at Ponta do Pargo on the western shore of Madeira. These changes were characterised by a decrease of approximately $50 \%$ in the PBL height at most of the affected grid points. As for PBL, there were significant alterations in the CAPE, CIN and BRN parameters that characterise the PBL structure and stability. These parameters have shown that, despite the changes that were present in the horizontal wind field, the change in the topography data set produced small changes to the PBL structure, resulting in a decrease in the CAPE and BRN in the highest peaks of Madeira and an increase in CIN near Ponta do Pargo. This was due to changes to the flow splitting pattern around Madeira. A relation between the thermodynamical and dynamical stability at play during this event could also be seen from the modelled results. The BRN differences show that these are dominated by differences in the thermodynamic properties and not by wind shear. It was also possible, through the $\theta_{v}$ cross sections, to see that changes to the vertical structure of the atmosphere occur not only when considering the averaged simulated period, but also at the time of the event, where a spatial lag for the positions where the air rises and condensates develops.

In addition, alterations in precipitation patterns and distribution between the CTL, SRTM and ASTER simulations over Madeira could also be observed. These are related to topographic features, such as the change in terrain slope and consequently in terrain forcing, resulting in an intensification of uplifting, which may result in an increase in precipitation and vice versa. Thereupon, an increase in precipitation over the mountainous ridges and a decrease in accumulated precipitation over the valley are consistent with changes associated with the topographic forcing.

Nonetheless, it was possible to see that these changes are correlated well with the differences between the topographical data sets.

For the CORINE simulation - which tested the impact of a new land-use data set on this extreme precipitation event - no statistically significant differences were found for the PBL structure. However, changes to the roughness length due to different land use produced changes to the TKE - a decrease in TKE in the mountainous region and an increase in the shore region of Madeira. This change was also noticeable in the 10-metre wind intensity. For this atmospheric variable, a significant increase was found in the mountainous region. This simulation did not show any statistically significant changes to the precipitation pattern over Madeira.

Comparing the simulated wind and precipitation results against observations, it was possible to see that there is low model skill for $u$ and $v$ wind components over Madeira for all the performed simulations. Furthermore, when using high-resolution topography data sets, a slight enhancement in model skill can be observed. However, this enhancement is small and not statistically significant. Kolmogorov-Smirnov testing shows that the simulations are from the same continuous distribution, with a $p$ value of 0.5109 . Considering the precipitation data, it could be seen that there is high model skill. However, the observed variability for precipitation is overestimated by the model for all simulations. The SRTM and ASTER simulations of precipitation presented a decrease, however small, in model skill when compared to the control simulation.

To evaluate these changes in more detail, four distinct Madeira regions, namely mountainous, shore, windward and leeward, were considered. Results show that, concerning the 
simulation of flow, the model performs better for altitudes higher than $800 \mathrm{~m}$ for all the simulations. It could also be seen that a small enhancement in model skill can be achieved for the leeward region when using the SRTM topography data set. For precipitation data, the opposite result can be observed and there is high model skill simulating precipitation for altitudes lower than $800 \mathrm{~m}$ for all performed simulations. Furthermore, a significant improvement in model skill in the leeward region was achieved using the SRTM topography data set. On the other hand, for the windward region, the differences between the simulations are small, resulting in a slightly lower SRTM skill. Nonetheless, one should take into consideration that the differences found for skill in these regions - especially the windward and leeward one - are not only caused by the use of a different topographical data set, but also due to the fact that stations located along the Madeira ridge are considered to be in the different regions for SRTM, ASTER and CTL as result of the differences in the location of the Madeira ridge in the SRTM when compared to all the other data sets.

Given this, one may conclude that the use of an highresolution data set within the WRF model leads to statistically significant changes to model results for this particular orographic extreme precipitation event, changing the 10metre wind intensity, PBL structure and precipitation patterns. Furthermore, when comparing it to observed data, it can be concluded that, overall, there is little model skill gain when using any of the high-resolution lower boundary condition data sets. However, when analysing specific regions of Madeira, SRTM and ASTER give an improvement in model skill in the windward region for precipitation and in the leeward region for wind. On the other hand, a decrease in model skill in simulating precipitation can be observed. The use of a higher-resolution data set in numerical weather model may therefore improve model skill in simulating topographically forced processes.

Acknowledgements. This study was supported by FEDER funds through the Programa Operacional Factores de Competitividade COMPETE and by Portuguese national funds through FCT Fundação para a Ciencia e a Tecnologia, within the framework of Project Urban Atmospheric Quality, Climate Change and Resilience, EXCL/AAG-MAA/0383/2012

Edited by: M.-C. Llasat

Reviewed by: three anonymous referees

\section{References}

Abrams, M., Hook, S., and Ramachandran, B.: ASTER User Handbook* Version 2, Jet Propulsion Laboratory, 4800, 135, 2002.

André, J., De Moor, G., Lacarrere, P., and Du Vachat, R.: Modeling the 24-hour evolution of the mean and turbulent structures of the planetary boundary layer, J. Atmos. Sci., 35, 1861-1883, 1978.
Bossard, M., Feranec, J., and Otahel, J.: CORINE land cover technical guide Addendum 2000, 2000.

Chen, F. and Dudhia, J.: Coupling an advanced landsurface/hydrology model with the Penn State/ NCAR MM5 modeling system. Part I: Model description and implementation, Mon. Weather. Rev., 129, 569-585, 2001.

Chen, F., Warner, T., and Manning, K.: Sensitivity of orographic moist convection to landscape variability: A study of the Buffalo Creek, Colorado, flash flood case of 1996, J. Atmos. Sci., 58, 3204-3223, 2001.

Colle, B.: Sensitivity of orographic precipitation to changing ambient conditions and terrain geometries: An idealized modeling perspective, J. Atmos. Sci., 61, 588-606, 2004.

Couto, F., Salgado, R., and Costa, M.: Analysis of intense rainfall events on Madeira Island during the 2009/2010 winter, Nat. Hazard. Earth. Sys., 12, 2225-2240, 2012.

Deardorff, J. W.: Three-dimensional numerical study of the height and mean structure of a heated planetary boundary layer, Bound.Lay. Meteorol., 7, 81-106, 1974.

Farr, T. G., Rosen, P. A., Caro, E., Crippen, R., Duren, R., Hensley, S., Kobrick, M., Paller, M., Rodriguez, E., Roth, L., Seal, D., Shaffer, S., Shimada, J., Umland, J., Werner, M., Oskin, M., Burbank, D., and Alsdorf, D.: The Shuttle Radar Topography Mission, Rev. Geophys., 45, 1-33, 2007.

Fiori, E., Comellas, A., Molini, L., Rebora, N., Siccardi, F., Gochis, D., Tanelli, S., and Parodi, A.: Analysis and hindcast simulations of an extreme rainfall event in the Mediterranean area: The Genoa 2011 case, Atmos. Res., 138, 13-29, 2014.

Fragoso, M., Trigo, R. M., Pinto, J. G., Lopes, S., Lopes, A., Ulbrich, S., and Magro, C.: The 20 February 2010 Madeira flashfloods: synoptic analysis and extreme rainfall assessment, Nat. Hazards Earth Syst. Sci., 12, 715-730, doi:10.5194/nhess-12715-2012, 2012.

Ghafarian, P., Azadi, M., Meshkatee, A. H., and Farahani, M. M.: Numerical simulation of the impact of Anatolian and Caucasus Mountains on the precipitation distribution over the Black Sea, Nat. Hazards Earth Syst. Sci., 12, 607-613, doi:10.5194/nhess12-607-2012, 2012.

Grell, G. A. and Dévényi, D.: A generalized approach to parameterizing convection combining ensemble and data assimilation techniques, Geophys. Res. Lett., 29, 1693, 2002.

Grumm, R.: The Madeira Island Floods of 20 February 2010, National Weather Service of the United States of America, http: //cms.met.psu.edu/sref/severe/2010/20Feb2010.pdf, 2010.

Hong, S. Y. and Lim, J. O. J.: The WRF Single-Moment 6-Class Microphysics Scheme (WSM6), J. Korean Meteor. Soc., 42, 129151, 2006.

Janjić, Z.: Nonsingular implementation of the Mellor-Yamada level 2.5 scheme in the NCEP Meso model, NCEP Office Note, 437, $61,2002$.

Janjić, Z. I.: The step-mountain coordinate: physical package, Mon. Weather. Rev., 118, 1429-1443, 1990.

Jiang, Q.: Moist dynamics and orographic precipitation, Tellus A, 55, 301-316, 2003.

Jiménez, P. A. and Dudhia, J.: Improving the Representation of Resolved and Unresolved Topographic Effects on Surface Wind in the WRF Model., J. Appl. Meteorol., 51, 2012. 
Keyser, D. and Anthes, R. A.: The applicability of a mixed-layer model of the planetary boundary layer to real-data forecasting, Mon. Weather. Rev., 105, 1351-1371, 1977.

Koletsis, I., Lagouvardos, K., Kotroni, V., and Bartzokas, A.: The interaction of northern wind flow with the complex topography of Crete Island - Part 1: Observational study, Nat. Hazards Earth Syst. Sci., 9, 1845-1855, doi:10.5194/nhess-9-1845-2009, 2009.

Koletsis, I., Lagouvardos, K., Kotroni, V., and Bartzokas, A.: The interaction of northern wind flow with the complex topography of Crete Island - Part 2: Numerical study, Nat. Hazards Earth Syst. Sci., 10, 1115-1127, doi:10.5194/nhess-10-11152010, 2010.

Kotroni, V., Lagouvardos, K., and Lalas, D.: The effect of the island of Crete on the Etesian winds over the Aegean Sea, Q. J. Roy. Meteor. Soc., 127, 1917-1937, 2001.

Kunz, M. and Kottmeier, C.: Orographic enhancement of precipitation over low mountain ranges. Part I: Model formulation and idealized simulations, J. Appl. Meteorol. Clim., 45, 1025-1040, 2006a.

Kunz, M. and Kottmeier, C.: Orographic enhancement of precipitation over low mountain ranges. Part II: Simulations of heavy precipitation events over southwest Germany, J. Appl. Meteorol. Clim., 45, 1041-1055, 2006b.

Levizzani, V., Laviola, S., Cattani, E., and Costa, M. J.: Extreme precipitation on the Island of Madeira on 20 February 2010 as seen by satellite passive microwave sounders, Europ. J. Remote Sens., 46, 475-489, 2013.

Luna, T., Rocha, A., Carvalho, A. C., Ferreira, J. A., and Sousa, J.: Modelling the extreme precipitation event over Madeira Island on 20 February 2010, Nat. Hazards Earth Syst. Sci., 11, 24372452, doi:10.5194/nhess-11-2437-2011, 2011.
Maussion, F., Scherer, D., Finkelnburg, R., Richters, J., Yang, W., and Yao, T.: WRF simulation of a precipitation event over the Tibetan Plateau, China - an assessment using remote sensing and ground observations, Hydrol. Earth Syst. Sci., 15, 1795-1817, doi:10.5194/hess-15-1795-2011, 2011.

Chou, M. -D., and Suarez, M. J.: A solar radiation parameterization for atmospheric studies, NASA Tech. Rep. Series on Global Modeling and Data Assimilation, NASA/TM-1999- 104606, Vol. 15, 40 pp., 2001.

Mlawer, E. J., Taubman, S. J., Brown, P. D. anf Lacono, M. J., and Clough, S. A.: Radiative transfer for inhomogeneous atmosphere: RRTM, a validated correlated-k model for the long-wave, J. Geophys. Res., 102, 16663-16682, 1997.

NCEP: The GFS Atmospheric Model. NCEP Office Note 442, Global Climate and Weather Modeling Branch, 2003.

Pielke, R.: Mesoscale meteorological modeling, 78, 676 pp, 2002.

Pineda, N., Jorba, O., Jorge, J., and Baldasano, J.: Using NOAA AVHRR and SPOT VGT data to estimate surface parameters: application to a mesoscale meteorological model, Int. J. Remote. Sens., 25, 129-143, 2004.

Shi, X., Wang, Y., and Xu, X.: Effect of mesoscale topography over the Tibetan Plateau on summer precipitation in China: a regional model study, Geophys. Res. Lett., 35, L19707, doi:10.1029/2008GL034740, 2008.

Skamarock, W. C., Klemp, J. B., Dudhia, J., Gill, D. O., Barke, D. M., Wang, W., and Powers, J. G.: A Description of the Advance Reaserch WRF version 3, NCAR Technical Note, 2008.

Vrochidou, A.-E. K. and Tsanis, I. K.: Assessing precipitation distribution impacts on droughts on the island of Crete, Nat Hazards Earth Syst. Sci., 12, 1159-1171, doi:10.5194/nhess-121159-2012, 2012. 